Department of Intensive Care Medicine, Prince of Wales Hospital, Sydney, Australia

2 Centre for Population Health and Western Clinical School, Western Sydney Local Health District and University of Sydney, North Parramatta, NSW, Australia

3 Woolcock Institute of Medical Research, University of Sydney, Glebe, NSW, Australia

Correspondence to: N Wilson nickwilson247@gmail.com Cite this as: BMJ2020;370:m3206 http://dx.doi.org/10.1136/bmj.m3206 Published: 20 August 2020

\section{Airborne transmission of covid-19}

\section{Guidelines and governments must acknowledge the evidence and take steps to protect the public}

\author{
Nick Wilson, Stephen Corbett, ${ }^{2}$ Euan Tovey ${ }^{3}$
}

In July, 239 scientists signed an open letter “appealing to the medical community and relevant national and international bodies to recognise the potential for airborne spread of covid-19." ${ }^{1}$ Although the World Health Organization conceded that "airborne transmission cannot be ruled out," the response was reserved and arguably mistaken in continuing to suggest that airborne and droplet transmission are discrete categories and that airborne transmission occurs only during medical "aerosol generating procedures." 2

WHO defines droplets as $\geq 5-10 \mu \mathrm{m}$ diameter and aerosols as $<5 \mu \mathrm{m}$. However, both can be generated as a continuum of particle sizes during numerous respiratory activities and their behaviours are not distinct. This has important practical implications for infection control, the prevention of outbreaks and superspreading events, and for the new social behaviours that are being implemented in an effort to control the pandemic.

Aerosols are generated when the surface tension of fluid lining the respiratory tract is overcome by force. ${ }^{3}$ The required forces can be created by rapid shearing air flows, vocal cord movement, and the open and closing of terminal airways-all of which are influenced by the type and force of respiratory activity. ${ }^{3}$ Heavy breathing, coughing, talking, and singing all generate aerosols, causing an exhalation plume of respiratory particles of varying sizes, containing potentially infective viral material..$^{-8}$ The high viral loads present in the pharynx early in the course of covid-19 make these aerosols a plausible cause of both pre-symptomatic and asymptomatic transmission, which is so effective in fuelling outbreaks and yet difficult to control.

The arbitrary 5-10 $\mu \mathrm{m}$ threshold commonly used to dichotomise airborne and droplet transmission has never been supported theoretically or experimentally. ${ }^{4}$ Studies in both humans and airflow models show that particles as large as $50 \mu \mathrm{m}$ can remain suspended and travel considerable distances..$^{48}$ Furthermore, airborne range is influenced by the force and volume of exhalation as well as the local humidity, temperature, and airflow. ${ }^{4}$

It is wrong to assume that droplets land only on exposed mucosal surfaces such as the eyes and mouth. ${ }^{4}$ Particles up to $50 \mu \mathrm{m}$ can be captured by inspiratory airflows and are deposited along the much more extensive surface area of the respiratory tract; particles below $10 \mu \mathrm{m}$ can penetrate as far as alveoli. The site of deposition may determine the viral dose required and severity of respiratory infection, as observed in influenza. ${ }^{8}$
The term "aerosol generating procedures" became popular after the 2003 SARS epidemic, when small retrospective studies found an association between transmission to healthcare workers and use of procedures such as endotracheal intubation and non-invasive ventilation. ${ }^{9}$ This weak (grade D) evidence has been misused to infer a causal link between procedural aerosols and infection despite the fact that aerosols were not measured during these studies. ${ }^{9}$ Furthermore, nurses were more commonly infected than doctors performing procedures, suggesting that proximity and time exposed to patients with respiratory distress are stronger determinants of risk than the procedures themselves. ${ }^{3}$ Acutely ill patients do present additional risk to health workers from coughing, laboured breathing, airway collapse, sputum production, and high viral load. ${ }^{3}$

Some supposedly risky procedures may even reduce infective emissions by reducing the physiological mechanisms that produce aerosols and by limiting the exhaled jet plume and directing expired gases through antiviral filters. ${ }^{3}$ A prospective study sampling aerosols during WHO defined aerosol generating procedures in patients with influenza $\mathrm{H} 1 \mathrm{~N} 1$ found no significant increase in airborne viral RNA. ${ }^{10}$

Currently, aerosol generating procedures for low risk patients are often delayed or denied, and when they do go ahead are conducted with meticulous and expensive airborne precautions, while higher risk patients who are coughing, talking, and breathless are cared for by staff wearing just a surgical mask. Retrospective studies from China have observed higher rates of SARS-CoV-2 infection among staff treating low risk patients and using droplet precautions than among those wearing respirators to treat higher risk patients. ${ }^{11} 12$

\section{Strong signals}

Since the 2003 SARS outbreak, research in aerobiology, physics, and computational fluid dynamics has advanced our understanding of aerosol generation and the carriage and fate of respiratory particles. ${ }^{146-81314}$ Airborne transmission of covid-19 is now the plausible cause of superspreading events in a call centre in Korea, a choir practice in Skagit County, US, and a restaurant in Guangzhou, China. ${ }^{1214}$ The pandemic is at a critical juncture, and these strong signals should not be ignored by politicians and public health leaders.

Urgent research is needed to better understand airborne transmission and measure viral aerosol outputs during respiratory activity and medical procedures. In the meantime, international guidance 
must acknowledge the weight of evidence supporting airborne transmission of covid-19 and include recommendations to promote effective preventive measures. How should infection control practice be changed if we provisionally accept that aerosols have an important role in viral transmission?

Inhalational risk may be reduced by social distancing, limiting interaction indoors, avoiding air recirculation, improved natural and artificial ventilation, and innovative engineering solutions which collect and neutralise aerosols to provide clean air in personal and community spaces. ${ }^{14}$ The infection risk associated with deep breathing, talking, and singing indoors is underappreciated and urgently needs attention.

Aerosol generating procedure is a misleading term, and its use probably leads to overestimation of risk in stable patients while proved aerosol generating activities such as coughing and talking are neglected. ${ }^{1}{ }^{8}$ The risk associated with individual procedures should instead be classified by measuring aerosol emissions, comparing them with those from other respiratory activities, and placing them in clinical context. In the interim, healthcare workers require access to respirator masks for all high risk encounters, not just during selected clinical procedures.

Controlling this pandemic is difficult when the fundamental science determining the response is misunderstood. Accepting the importance of airborne transmission may prove a crucial breakthrough and should not be delayed further.

Competing interests: We have read and understood BMJ policy on declaration of interests and have no interests to declare.

Provenance and peer review: Not commissioned; externally peer reviewed.

1 Morawska L, Milton DK. It is time to address airborne transmission of covid-19. Clin Infect Dis 2020; doi: 10.1093/cid/ciaa939 pmid: 32628269

2 World Health Organisation. Scientific brief. Transmission of SARS-CoV-2: implications for infection prevention precautions. 2020. https://www.who.int/news-room/commentaries/detail/transmissionof-sars-cov-2-implications-for-infection-prevention-precautions

3 Wilson NM, Norton A, Young FP, Collins DW. Airborne transmission of severe acute respiratory syndrome coronavirus-2 to healthcare workers: a narrative review. Anaesthesia2020;75:1086-95. doi: 10.1111/anae.15093 pmid: 32311771

4 Zhang N, Chen W, Chan PT, Yen HL, Tang JW, Li Y. Close contact behavior in indoor environment and transmission of respiratory infection. Indoor Air 2020;30:645-61. doi: 10.1111/ina.12673 pmid: 32259319

5 Asadi S, Wexler AS, Cappa CD, Barreda S, Bouvier NM, Ristenpart WD. Aerosol emission and superemission during human speech increase with voice loudness. Sci Rep 2019;9:2348. doi: 10.1038/s41598-019-38808-z pmid: 30787335

6 Morawska L, Johnson GR, Ristovski ZD, etal. Size distribution and sites of origin of droplets expelled from the human respiratory tract during expiratory activities. J Aerosol Sci 2009;40:256-69doi: 10.1016/j.jaerosci.2008.11.002.

7 Wei J, Li Y. Airborne spread of infectious agents in the indoor environment. Am J Infect Control 2016;44(Suppl):S102-8. doi: 10.1016/j.ajic.2016.06.003 pmid: 27590694

8 Fennelly KP. Particle sizes of infectious aerosols: implications for infection control. Lancet Respir Med 2020; pmid: 32717211

9 Tran K, Cimon K, Severn M, Pessoa-Silva CL, Conly J. Aerosol generating procedures and risk of transmission of acute respiratory infections to healthcare workers: a systematic review. PLoS One 2012;7:. doi: 10.1371/journal.pone.0035797 pmid: 22563403

10 Thompson KA, Pappachan JV, Bennett AM, etalEASE Study Consortium. Influenza aerosols in UK hospitals during the H1N1 (2009) pandemic--the risk of aerosol generation during medical procedures. PLoS One 2013;8:. doi: 10.1371/journal.pone.0056278 pmid: 23418548

11 Lai X, Wang M, Qin C, etal. Coronavirus disease 2019 (COVID-2019) infection among health care workers and implications for prevention measures in a tertiary hospital in Wuhan, China. JAMA Netw Open 2020;3:. doi: 10.1001/jamanetworkopen.2020.9666 pmid: 32437575

12 Zhong Q, Liu YY, Luo Q, etal. Spinal anaesthesia for patients with coronavirus disease 2019 and possible transmission rates in anaesthetists: retrospective, single-centre, observational cohort study. Br J Anaesth 2020;124:670-5. doi: 10.1016/j.bja.2020.03.007 pmid: 32234250

13 Hamner L, Dubbel P, Capron I, etal. High SARS-CoV-2 attack rate following exposure at a choir practice-Skagit County, Washington, March 2020. MMWR Morb Mortal Wkly Rep 2020;69:606-10. doi: 10.15585/mmwr.mm6919e6 pmid: 32407303
14 American Society of Heating. Refrigerating and air-conditioning engineers (ASHRAE) position document on infectious aerosols. https://www.ashrae.org/technical-resources/resourcesAccessed10/8/2020

This article is made freely available for use in accordance with BMJ's website terms and conditions for the duration of the covid-19 pandemic or until otherwise determined by BMJ. You may use, download and print the article for any lawful, non-commercial purpose (including text and data mining) provided that all copyright notices and trade marks are retained. 